\title{
Observation of gaseous and particulate products of monoterpene oxidation in forest atmospheres
}

\author{
Jianzhen Yu ${ }^{1}$, Robert J. Griffin ${ }^{2}$, David R. Cocker III ${ }^{1}$, Richard C. Flagan ${ }^{2}$, and \\ John H. Seinfeld ${ }^{3 *}$ \\ ${ }^{1}$ Department of Environmental Engineering Science, ${ }^{2}$ Department of Chemical Engineering, ${ }^{3}$ Division of \\ Engineering and Applied Science and Department of Chemical Engineering, California Institute of Technology, \\ Pasadena, CA 91125
}

\author{
Pierrette Blanchard \\ Environment Canada, Ontario Region, Downsview, Ontario, Canada, M3H 5T4
}

\begin{abstract}
Atmospheric oxidation of biogenic hydrocarbons, such as monoterpenes, is estimated to be a significant source of global aerosol. Whereas laboratory studies have established that photochemical oxidation of monoterpenes leads to aerosol formation, there are limited field studies detecting such oxidation products in ambient aerosols. Drawing on prior results of monoterpene product analysis under controlled smog chamber conditions, we have identified organic aerosol components attributable to monoterpene oxidation in two forest atmospheres, Kejimkujik National Park, Nova Scotia, Canada, and Big Bear, San Bernardino National Forest, California, U.S.A. The major identified aerosol products derived from $\alpha$-pinene and $\beta$-pinene oxidation include pinic acid, pinonic acid, norpinonic acid and its isomers, hydroxy pinonaldehydes, and pinonaldehyde, concentrations of which in the aerosol phase are in the sub ng $\mathrm{m}^{-3}$ range. Identification of oxidation products in atmospheric aerosol samples serves as direct evidence for aerosol formation from monoterpenes under ambient conditions.
\end{abstract}

\section{Introduction}

The atmospheric aerosol-forming potential of biogenic hydrocarbons was noted as early as 1960 [Went, 1960], and laboratory studies have established that atmospheric oxidation of monoterpenes and sesquiterpenes leads to aerosol formation [Hoffmann et al., 1997; Griffin et al., 1999]. Production of biogenic secondary organic aerosols on a global basis is estimated to range between 30 and $270 \mathrm{Tg}^{\mathrm{year}}{ }^{-1}$, a magnitude comparable to the production of biogenic and anthropogenic sulfate aerosols [Andreae and Crutzen, 1997].

Monoterpenes are important constituents of aerosolforming biogenic compounds [Griffin et al., 1999]. Despite numerous field measurements of gas-phase monoterpenes [e.g. Roberts et al., 1983; Zimmerman et al., 1988; Clement et al., 1990; Biesenthal et al., 1998], there are few field studies in which their oxidation products have been measured. Recent advances in analytical methods have now made it possible to

\footnotetext{
" To whom correspondence should be directed.
}

Copyright 1999 by the American Geophysical Union.

Paper number 1999GL900169.

0094-8276/99/1999GL900169\$05.00 detect and identify such secondary organic aerosol components, which generally have multiple polar oxygenated functional groups [Yu et al., 1998; 1999]. Ambient measurements of biogenic hydrocarbon oxidation products in the atmospheric aerosol provide the link that establishes the importance of this source to global tropospheric aerosol. We present here measurements of monoterpene-derived aerosol components in two forest atmospheres, Kejimkujik National Park, Nova Scotia, Canada, and San Bernardino National Forest, California, U.S.A.

\section{Ambient Sampling and Analysis}

The measurement site in Kejimkujik National Park ( $44^{\circ} 26^{\prime}$ $\mathrm{N}, 62^{\circ} 12^{\prime} \mathrm{W}$ ) is situated in the Atlantic province of Nova Scotia. The park is in a forest consisting of a mixture of twothirds coniferous and one-third deciduous trees [Bottenheim et al., 1994]. Ambient mixing ratios of $\alpha$-pinene and $\beta$-pinene were determined on-line using a Hewlett-Packard GC/MS [Biesenthal et al., 1998]. Aerosol samples were collected in July, 1996 over a period of 2 to 3 days at a flow rate of $10 \mathrm{~L}$ $\mathrm{min}^{-1}$ on $47 \mathrm{~mm}$ quartz fiber filters. Since the aerosol samples were collected in a field campaign that did not include characterizing semivolatile organics as one of its goals, adequate sampling devices were not implemented to minimize sampling artifacts for semivolatiles. Collection of two filter samples analyzed in this work commenced on July 5 and July 8 , based on a sampled air volume of 26.94 and $44.72 \mathrm{~m}^{3}$, respectively. The diurnal temperature during the sampling period ranged from 11 to $21^{\circ} \mathrm{C}$, and the relative humidity from $13 \%$ to $50 \%$ [Leaitch et al., 1999].

The measurement site in the San Bernardino National Forest is located in Big Bear Valley $\left(34^{\circ} 13^{\prime} \mathrm{N}, 116^{\circ} 49^{\prime} \mathrm{W}\right.$ ), $\mathrm{CA}$, at an elevation of 2150 meters. Lodgepole pines, pinion pines, oaks, and Douglas firs are major tree species in this area. Hourly measurements of gas-phase monoterpenes were achieved by collecting $300 \mathrm{~L}$ of air on Tenax tubes, and were then analyzed by a Hewlett-Packard GC/MS following thermal desorption using a Tekmar AeroTrap Desorber 6000 . Two types of aerosol sampling devices were deployed, one consisting of one or two denuders followed by a Teflon impregnated glass fiber filter, and the other one consisting of two $47 \mathrm{~mm}$ filters--a Teflon impregnated glass fiber filter followed by a glass fiber filter. Two sampling trains were set up for each type of sampling device. The sampling train with 
Table 1. Monoterpene Oxidation Products Detected at Forest Sites

\begin{tabular}{|c|c|c|}
\hline Name & Structure & note \\
\hline $\begin{array}{l}\mathrm{C}_{8} \mathrm{H}_{12} \mathrm{O}_{4} \\
\text { norpinic acid } \\
\mathrm{MW}=172\end{array}$ & & $a, b$ \\
\hline $\begin{array}{l}\mathrm{C}_{9} \mathrm{H}_{14} \mathrm{O}_{4}{ }^{*} \\
\text { pinic acid } \\
\mathrm{MW}=186\end{array}$ & & $c, d$ \\
\hline $\begin{array}{l}\mathrm{C}_{9} \mathrm{H}_{14} \mathrm{O}^{*} \\
\text { nopinone } \\
\mathrm{MW}=138\end{array}$ & & $e, f$ \\
\hline $\begin{array}{l}\mathrm{C}_{9} \mathrm{H}_{14} \mathrm{O}_{2} \\
\text { hydroxy pina } \\
\text { ketones } \\
\mathrm{MW}=154\end{array}$ & & $e, f$ \\
\hline
\end{tabular}

$\begin{aligned} & \mathrm{C}_{9} \mathrm{H}_{14} \mathrm{O}_{3} \\ & \text { norpinonic acid } \\ & \text { its isomers } \\ & \mathrm{MW=170} \\ & \mathrm{C}_{10} \mathrm{H}_{16} \mathrm{O}_{3}{ }^{*} \\ & \text { pinonic acid } \\ & \mathrm{MW}=184\end{aligned}$
$\mathrm{C}_{10} \mathrm{H}_{16} \mathrm{O}_{4}$
hydroxy
pinonic acid
$\mathrm{MW}=200$

* identification confirmed with an authentic standard.

known product of $\mathrm{O}_{3}$ oxidation of $\alpha$-pinene and $\beta$-pinene.

${ }^{b}$ detected in Kejimkujik samples.

${ }^{c}$ known product of $\mathrm{O}_{3}$ oxidation of $\alpha$-pinene, $\beta$-pinene, sabinene and $\Delta^{3}$-carene.

detected in Kejimkujik and Big Bear samples.

known product of $\mathrm{O}_{3}$ oxidation of $\beta$-pinene.

$f$ detected in Big Bear denuder samples.

${ }^{g}$ known product of $\mathrm{O}_{3}$ oxidation of $\alpha$-pinene.

h detected in Big Bear denuder and filter samples.

possible product of $\mathrm{O}_{3}$ oxidation of limonene.

two denuders was used to quantify denuder collection efficiency. Samples were collected from 19:00 PDT Aug. 31 to 13:00 PDT Sep. 1, 1998 at a flow rate of $22 \mathrm{~L} \mathrm{~min}^{-1}$. The back filter in the two-filter set-up was used for assessing filter adsorption of gaseous semivolatile organics. Ambient temperature during the sampling period varied from 18 to $32^{\circ} \mathrm{C}$, and relative humidity ranged from $20 \%$ to $59 \%$.

Denuder samples were extracted on-site, and all samples were stored at $0^{\circ} \mathrm{C}$ before analysis. The procedure for extraction, subsequent processing, and analysis of denuder and filter samples has been described elsewhere [ $\mathrm{Yu}$ et al., 1999]. The extracts of denuder and filter samples were derivatized by $(2,3,4,5,6$-pentafluorobenzyl) hydroxy amine (PFBHA) and N, O-bis (trimethylsilyl)-trifluoroacetamide. By this procedure, carbonyl functional groups of the oxidation products were converted into oximes, and carboxyl and hydroxyl function groups were converted into trimethylsilyl

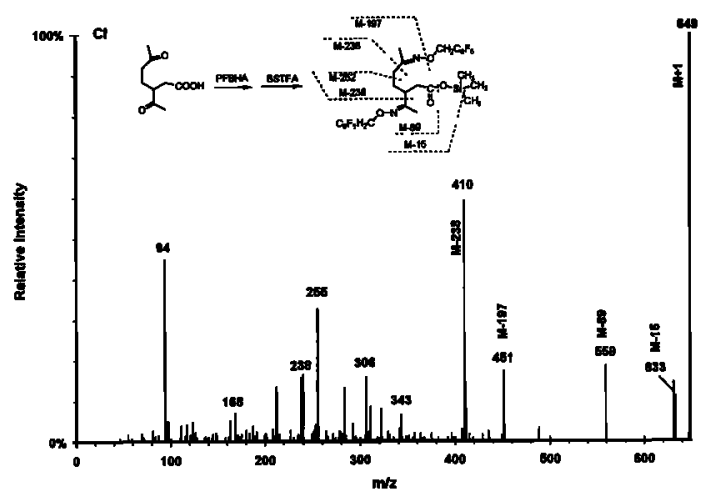

Figure 1. Chemical ionization mass spectrum for the derivative of a $\mathrm{C}_{9}$ dioxo carboxylic acid compound detected in aerosol samples.

(TMS) groups. The resulting derivatives were then analyzed by GC/MS, using both electronic ionization (EI) and chemical ionization (CI) modes for identification and quantification. Blank filters in both studies were treated and analyzed following the same procedures applied to the sample filters. Quantification of products for which authentic standards do not exist was achieved by using surrogate compounds that have the same functional groups and approximate carbon numbers [Yu et al., 1999].

\section{Results and Discussion}

\subsection{Identification of Monoterpene Oxidation Products}

Oxidation products of $\alpha$-pinene and $\beta$-pinene in the ambient samples were identified by comparing GC chromatograms and mass spectra of the ambient samples with those obtained from controlled chamber experiments. Table 1 lists the chemical structures of the monoterpene oxidation products observed. Established products from oxidation of $\alpha$ pinene and $\beta$-pinene include pinic acid, norpinic acid, pinonaldehyde, norpinonaldehyde, hydroxy pinonaldehydes, pinonic acid, norpinonic acid, hydroxy pinonic acid, hydroxy pina ketones, and nopinone. An unidentified product (denoted $\mathrm{X}_{1}$ ), having two carbonyl groups and a molecular weight of 198 as determined from its EI and CI mass spectra, is observed in both laboratory generated aerosol in the $\alpha$ pinene $/ \mathrm{O}_{3}$ system and ambient aerosols at both sites. Besides oxidation products derived from $\alpha$-pinene and $\beta$-pinene, a compound denoted $\mathrm{X}_{2}$, detected in samples from both sites, is identified as a $\mathrm{C}_{9}$ dioxo mono-carboxylic acid, having a molecular weight of 186 . Fig. 1 displays the CI mass spectrum for the PFBHA and TMS derivative of this compound $\mathrm{X}_{2}$. The molecular weight and some structural information can be determined from the mass spectrum [Yu et al., 1998]. Ozone oxidation of limonene could lead to the formation of a $\mathrm{C}_{9}$ dioxo mono-carboxylic acid, 3-acetyl-6oxo-heptanoic acid, as illustrated in Fig. 2 [Horie et al., 1994; Neeb et al., 1997]. The mass spectrum shown in Fig. 1 is consistent with that expected for this compound.

\subsection{Kejimkujik Samples}

Table 2 lists mixing ratios of three monoterpenes and concentrations of various monoterpene oxidation products in the aerosol phase in two filter samples collected in Kejimkujik National Park. All the identified oxidation products are detected at the sub-nanogram $\mathrm{m}^{-3}$ level. The presence of monoterpene oxidation products in filter samples correlates with the observation that aerosol volume increased 


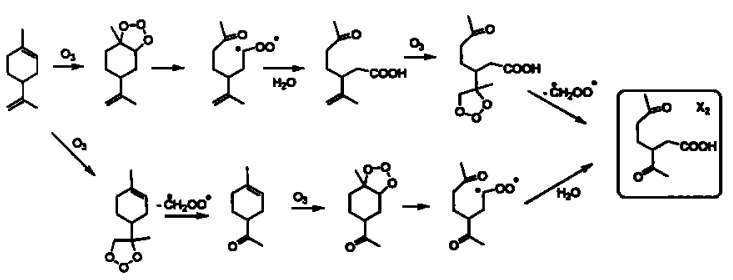

Figure 2. Formation pathways for a $C_{9}$ dioxo carboxylic acid product from oxidation of limonene.

with the decrease in $\alpha$-pinene and $\beta$-pinene during the same sampling period at this same site [Leaitch et al., 1999].

\subsection{Big Bear Samples}

Table 3 lists the mixing ratios of six monoterpenes and the concentrations of various monoterpene oxidation products detected in both the gas and aerosol phases in the San Berhardino National Forest of California. The denuder/filter set-up at this site allowed simultaneous determination of semi-volatile compounds in both gas and particulate phases. Species collected by the denuder represent those in the gas phase. Denuder collection efficiencies for the products in Table 3 range from 0.88 to 1.0. Gas-phase concentrations as determined from denuder samples have been corrected for the denuder collection efficiency for each product. As evident in Table 3, the monoterpene oxidation products at this site predominately exist in the gas phase. A number of oxidation products were detected solely in the gas phase due to either their high volatility (e.g. nopinone, hydroxy pina ketones, and norpinonaldehyde) or to such a low concentration in the air that the amount partitioned to the aerosol phase is below detection limit (e.g. norpinonic acid and hydroxy pinonic acid).

Comparison of filter samples in the presence and absence of a denuder in front of the sampling train indicates that the filter-only technique suffers a positive sampling artifact. Semivolatile products are also detected on the back filter in the filter-only set-up, which is evidence for filter adsorption of gaseous semivolatile organics. Concentrations obtained via the filter-only technique are $120 \%-137 \%$ higher than those obtained using the denuder/filter sampling device for

Table 2. Monoterpene Oxidation Products in Filter Samples Collected in Kejimkujik National Park, Nova Scotia

\begin{tabular}{|c|c|c|c|c|c|}
\hline$\underset{\mathrm{mixir}}{\mathbf{m}}$ & onoterpen & & Product & Conc. ( & $n g \mathbf{~ m}^{-3}$ ) \\
\hline & & $960708^{\mathrm{a}}$ & rToduct & $960705^{a}$ & $960708^{a}$ \\
\hline$\overline{\alpha \text {-pinene }}$ & $88-283$ & $147-642$ & norpinic acid ${ }^{6}$ & 0.34 & 0.34 \\
\hline$\beta$-pinene & $69-401$ & $209-864$ & pinic acid & 0.48 & 0.59 \\
\hline camphene & $60-442$ & $156-561$ & norpinonic acid & 0.24 & 0.04 \\
\hline & & & pinonic acid & 0.39 & 0.13 \\
\hline & & & pinonaldehyde ${ }^{d}$ & 0.19 & 0.08 \\
\hline & & & hydroxy & 0.12 & $\mathrm{ND}^{\mathrm{e}}$ \\
\hline & & & $\mathrm{X}_{1}$ & 0.12 & 0.13 \\
\hline & & & $\mathrm{X}_{2}{ }^{\mathrm{c}}$ & 0.19 & 0.13 \\
\hline
\end{tabular}

\footnotetext{
Dates when aerosol samples commenced

b Quantified using the calibration factor and recovery for pinic acid.

c Quantified using the calibration factor and recovery for pinonic acid.

${ }_{d}$ Quantified using the calibration factor and recovery for 5-methylcyclohexane-1,3-dione.

Not detectable.
}

Table 3. Gaseous and Particulate Monoterpene Oxidation Products in Samples Collected in San Bernardino National Forest, California

\begin{tabular}{|c|c|c|c|c|c|}
\hline \multicolumn{3}{|c|}{$\begin{array}{c}\text { Monoterpene } \\
\text { mixing ratio (pptv) }\end{array}$} & \multirow[t]{2}{*}{ Product } & \multicolumn{2}{|c|}{ conc. $\left(\mathrm{ng} \mathrm{m}^{-3}\right)^{\mathbf{a}}$} \\
\hline 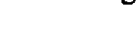 & Range & Ávg. & & gas & aerosol \\
\hline$\overline{\alpha-p i n e n e}$ & $22-119$ & 63 & pinic acid & $\overline{11.5}$ & 0.5 \\
\hline$\beta$-pinene & $16-111$ & 50 & $\begin{array}{l}\text { norpinonic acid } \\
\& \text { its isomers }\end{array}$ & 12.3 & $\mathrm{ND}^{\mathrm{b}}$ \\
\hline limonene & $13-63$ & 27 & pinonic acid & 202.4 & 0.8 \\
\hline camphene & $7-76$ & 36 & norpinonaldehyde & 4.7 & ND \\
\hline$\Delta^{3}$-carene & $2-21$ & 10 & pinonaldehyde & 280 & 1.0 \\
\hline junipene & $0-8$ & 5 & $\begin{array}{l}\text { hydroxy } \\
\text { pinonaldehydes }\end{array}$ & 16.8 & 0.5 \\
\hline & & & $\mathbf{X}_{1}$ & 3.3 & 0.2 \\
\hline & & & $X_{2}$ & 17.8 & 0.8 \\
\hline & & & hydroxy pinonic acid & 9.0 & ND \\
\hline & & & hydroxy pina ketones & 18.0 & ND \\
\hline & & & nopinone $\&$ isomers ${ }^{c}$ & 132.9 & ND \\
\hline
\end{tabular}

\footnotetext{
average values of two samples.

${ }^{b}$ Not detectable.

${ }^{c}$ Possible isomers include primary carbonyl products from ozone oxidation at the external $\mathrm{C}=\mathrm{C}$ bond in limonene and camphene.
}

sampling conditions employed at the Big Bear site. McDow and Huntzicker [1990] observed a significant increase of positive artifact with decreasing filter face velocity for a quartz fiber filter. They estimated that at low organic carbon concentrations, the correction factor due to adsorption could exceed $50 \%$ at a sampling face velocity of $40 \mathrm{~cm} \mathrm{~s}^{-1}$. Considering the lower face velocity $\left(-20 \mathrm{~cm} \mathrm{~s}^{-1}\right)$, the positive artifact observed at the Big Bear site is in general agreement with McDow and Huntzicker's results. Therefore, the filteronly technique is not adequate for measurements of biogenic oxidation products in the aerosol phase. Concentrations derived from the two Kejimkujik filter samples likely overestimate the actual aerosol concentrations for this reason.

\section{Comparison with Prior Field Studies}

Previous field measurements of particulate-phase terpene oxidation products have been limited to pinonaldehyde, pinonic acid, and nopinone. A recent study has also measured ambient concentrations of pinic acid and norpinonic acid [Kavouras et al., 1999]. Yokouchi and Ambe [1985] measured pinonaldehyde concentrations of $2-3 \mathrm{ng} \mathrm{m}^{-3}$ in aerosol samples collected in the cedar forest at Kiyosumi and in the pine forest at Tsukuba in Japan in summer time. Satsumabayashi $e t$ al. [1990] detected pinonaldehyde at $30 \mathrm{ng}$ $\mathrm{m}^{-3}$ and $100 \mathrm{ng} \mathrm{m}^{-3}$ at two mountainous sites in central Japan. Calogirou et al. [1997] observed pinonaldehyde near Ispra, Italy at $90 \mathrm{ng} \mathrm{m}^{-3}$ using DNPH-coated cartridges. Since an ozone scavenger was used in this study, which also collected particles, this concentration reflects that in the gas-phase. Kavouras et al. [1998] reported aerosol concentrations for pinonic acid, nopinone, and pinonaldehyde ranging from 9$140,0.3-13.2$, and $0.17-32.1 \mathrm{ng} \mathrm{m}^{-3}$, respectively, at a forest site in Portugal. In the most recent study, Kavouras et al. [1999] deployed a denuder/filter sampling device to measure monoterpene oxidation products in both gas and aerosol phases in a conifer forest located in Pertouli in Central Greece. They reported diurnal particulate concentrations for pinonic acid, pinic acid, norpinonic acid, pinonaldehyde, and nopinone to be $1.0-25.7,0.4-4.4,0.2-5.4,0.2-1.2$, and $0-0.4$ ng $\mathrm{m}^{-3}$, respectively. In this study, simultaneous measurements of Aitken nuclei also provided evidence that 
the photooxidation products from biogenic precursors play a role in forming new particles.

Considering the many factors influencing concentrations of aerosol-phase monoterpene oxidation products, the wide variability of ambient concentrations among the six studies is not surprising. Pinonaldehyde, for example, was measured in all six studies with concentrations ranging from under detection limit to $100 \mathrm{ng} \mathrm{m}^{-3}$. Concentrations of precursor monoterpenes and atmospheric oxidants govern formation rate of the products. The higher mixing ratios of $\alpha$-pinene ( 0 $3.2 \mathrm{ppbv}$ ) and $\beta$-pinene (0-1.4 ppbv) may partly account for the more plentiful oxidation products in the aerosol phase in the study of Kavouras et al. [1999]. The aerosol-phase fraction of a semi-volatile organic compound, such as any of the monoterpene oxidation products, is known to be controlled by available organic aerosol mass and the compound's gas-aerosol partitioning coefficient, which, in turn, is a function of temperature and the overall aerosol chemical composition [Odum et al., 1996; Jang et al., 1997; Jang and Kamens, 1999; Yu et al., 1999]. Besides these factors intrinsic to aerosol formation, sampling artifacts can also introduce variability in the reported concentrations. For example, as noted earlier, the filter-only technique suffers a positive artifact from adsorption of gas-phase semi-volatiles onto the filter surface, whereas volatilization of aerosol-phase semi-volatiles introduces a negative artifact, which depends on sampling rate and filter area [McDow and Huntzicker, 1990]. In addition, a number of products (e.g. pinonaldehyde and norpinonic acid) do not have available commercial standards, and different surrogate compounds have been used to estimate their concentrations.

\section{Conclusions}

We have detected in two forest atmospheres a number of gas- and aerosol-phase products from oxidation of $\alpha$-pinene and $\beta$-pinene, including pinic acid, norpinic acid, pinonic acid, norpinonic acid and its isomers, pinonaldehyde, norpinonaldehyde, hydroxy pinonaldehydes, hydroxy pinonic acid, and nopinone. In addition, a $C_{9}$ dioxo carboxylic acid, detected at both sites, is postulated to be 3-acetyl-6-oxoheptanoic acid, a product expected from ozone oxidation of limonene. Identification of monoterpene oxidation products in aerosol samples serves as direct evidence for aerosol formation from monoterpenes under ambient conditions.

Acknowledgements. This work was supported by U.S. National Science Foundation grant ATM-9614105. We would like to thank J.F. Hopper for leading the Kejimkujik organic aerosol project, A. Pinette and A. J. Gallant for their technical assistance, and J. W. Bottenheim, T. A. Biesenthal, and W. R. Leaitch for data and helpful discussions.

\section{References}

Andreae, M. O. and P.J. Crutzen, Atmospheric aerosols: Biogeochemical sources and role in atmospheric chemistry, Science, 276, 1052-1055, 1997.

Biesenthal, T. A., J.W. Bottenheim, P.B. Shepson and P.C. Brickell, The chemistry of biogenic hydrocarbons at a rural site in eastern Canada, J. Geophys. Res., 103, 25487-25498, 1998.

Bottenheim, J. W., A. Sirois, K.A. Brice and A.J. Gallant, Five years of continuous observation of PAN and ozone at a rural location in Eastern Canada, J. Geophys. Res., 99, 5333-5352, 1994.

Calogirou, A., M. Duane, D. Kotzias, M. Lahaniati and B.R. Larsen, Polyphenylenesulfide NOXON, an ozone scavenger for the analysis of oxygenated terpenes in air, Atmos. Environ., 13, 2741$2751,1997$.

Clement, B., M.L. Riba, R. Leduc, M. Haziza and L. Terres, Concentration of monoterpenes in a maple forest in Quebec, Atmos. Environ., 24A, 2513-2516, 1990.

Griffin, R. J., D.R. Cocker, R.C. Flagan and J.H. Seinfeld, Organic aerosol formation from the oxidation of biogenic hydrocarbon., $J$. Geophys. Res., 104, 3555-3568, 1999.

Hoffmann, T, J.R. Odum, F. Bowman, D. Collins, D. Klockow, R.C. Flagan and J.H. Seinfeld, Formation of organic aerosols from the oxidation of biogenic hydrocarbons, J. Atmos. Chem, 26, 189-222, 1997.

Horie, O., P. Neeb, S. Limbach and G.K. Moortgat, Formation of formic acid and organic peroxides in the ozonolysis of ethene with added water vapor, Geophys. Res. Lett., 21, 1523-1526, 1994.

Jang, $M$ and R.M. Kamens, Newly characterized products and composition of secondary aerosols from the reaction of $\alpha$-pinene with ozone. Atmos. Environ., 33, 459-474, 1999.

Jang, M., Kamens, R. M., Leach, K. B., and Strommen, M. R. (1997). A thermodynamic approach using group contribution methods to model the partitioning of semivolatile organic compounds on atmospheric particulate matter. Environ. Sci. Technol., 3I, 2805-2811.

Kavouras, I. G., N. Mihalopoulos and E.G. Stephanou, Formation of atmospheric particles from organic acids produced by forests. Nature, 395, 683-686, 1998.

Kavouras, I. G., N. Mihalopoulos and E.G. Stephanou, Formation and gas/particle partitioning of monoterpenes photooxidation products over forests. Geophys. Res. Lett.,26, 55-58, 1999.

Leaitch, W. R., J.W. Bottenheim, T.A. Biesenthal, S.M. Li, P.S. K Liu, K. Asalien, H. Dryfhout-Clark and F. Hopper, A case study of gas-to-particle conversion in an eastern Canadian Forest, $J$. Geophys. Res., 1999 (in press).

McDow, S. R. and J.J. Huntzicker, Vapor adsorption artifact in the sampling of organic aerosol: Face velocity effects. Atmos. Environ., 24A, 2563-2571, 1990.

Neeb, P., F. Sauer and O. Horie, Formation of hydroxymethyl hydroperoxide and formic acid in alkene ozonolysis in the presence of water vapor, Atmos. Environ., 31, 1417-1423, 1997

Odum, J. R., T. Hoffmann, F. Bowman, D. Collins, R.C. Flagan and J.H. Seinfeld, Gas/particle partitioning and secondary organic aerosol yields. Environ. Sci. Technol., 30, 2580-2585, 1996.

Roberts, J. M., F.C. Fehsenfeld, D. L. Albritton and R.E. Sievers, Measurement of monoterpene hydrocarbons at Niwot Ridge, Colorado. J. Geophys. Res., 88, 667-678, 1983

Satsumabayashi, H., H. Kurita, Y. Yokouchi and H. Ueda, Photochemical formation of particulate dicarboxylic acids under long-range transport in Central Japan. Atmos. Environ., 24A, 1443-1450, 1990.

Went, F. W., Blue hazes in the atmosphere. Nature, 187, 641-643, 1960.

Yokouchi, Y. and Y. Ambe, Aerosols formed from the chemical reaction of monoterpenes and ozone. Atmos. Environ., 19, 12711276,1985 .

Yu, J., R.C. Flagan and J.H. Seinfeld, Identification of products Containing $-\mathrm{COOH},-\mathrm{OH}$, and $-\mathrm{C}=\mathrm{O}$ in atmospheric oxidation of hydrocarbons. Environ. Sci. Technol., 32, 2357-2370, 1998.

Yu, J., D.R. Cocker III, R.J. Griffin, R.C. Flagan and J.H. Seinfeld, Gas-phase ozone oxidation of monoterpenes: Gaseous and particulate product. J. Atmos. Chem., 104, 3555-3568, 1999.

Zimmerman, P. R., J. P. Greenberg and C. E.Westberg, Measurement of atmospheric hydrocarbons and biogenic emission fluxes in the Amazon boundary layer. J. Geophys. Res., 93, 1407-1416, 1988.

D. Cocker and J. Yu, Dept. of Environmental Engineering Science; R. Flagan and R. Griffin, Dept. of Chemical Engineering; J. Seinfeld, Div. of Engineering and Applied Science and Dept. of Chemical Engineering, California Institute of Technology, Pasadena, CA 91125 . (e-mail: jianyu@its.caltech.edu; cocker@its.caltech.edu; robertg@its.caltech.edu; flagan@cheme.caltech.edu and seinfeld @its.caltech.edu)

Pierrette Blanchard, Environment Canada, Ontario Region Downsview, Ontario, Canada, M3H 5 T4 (e-mail: Pierrette.Blanchard (aec.gc.ca)

(Received December 21, 1998; revised February 19, 1999; accepted February 26, 1999.) 